\title{
DIFFUSE CUTANEOUS LEISHMANIASIS WITH ATYPICAL ASPECTS
}

ACHILÉA L. BITTENCOURT, M.D., ALDINA BARRAL, M.D.,

JACKSON M.L. COSTA, M.D., ANA CRISTINA SALDANHA, M.D.,

FERNANDO BADARÓ, M.D., MANOEL BARRAL-NETTO, M.D., AND LUIZ A.R. FREITAS, M.D.

\begin{abstract}
A 16-year-old man had long-standing diffuse cutaneous leishmaniasis with the following characteristics: diffuse infiltrated lesions rich in amastigotes, absence of mucosal involvement, and lack of parasite-specific cell-mediated immune response. In situ identification of Leishmania mexicana amazonensis was achieved by the use of monoclonal antibodies. Clinically, as an atypical finding there was deep and extensive ulceration in the lower limbs. Histologically, an atypical characteristic was the presence of a high number of eosinophils in the infiltrate predominantly in the ulcerated lesion. Ultrastructurally, parasitized and lysed eosinophils with dispersion of their granules were seen in the vicinity of parasitized or lysed macrophages.
\end{abstract}

Diffuse cutaneous leishmaniasis (DCL) is a polar form of cutaneous leishmaniasis characterized by largely disseminated nodules, abundance of parasites throughout the course of disease, and absence of parasite-specific cell-mediated immune response. Microscopically, DCL is represented by a monomorphic cellular infiltrate of vacuolated and heavily parasitized macrophages, sometimes with foci of lymphoplasmocyte infiltration. ${ }^{1-5} \mathrm{We}$ present here an atypical case of DCL, which exhibited extensive ulcerations and, microscopically, an intense eosinophil infiltrate, a characteristic seen for the first time in this form of human leishmaniasis.

\section{Case Report}

A 16-year-old man presented with a history of several nodular ulcerated lesions involving the whole body since the age of one year. He was born in Pinheiro (Maranhão State, Brazil). He had previously received several courses of pentavalent antimonial (Glucantime) and amphotericin B with-

From the Departments of Pathology and Internal Medicine, School of Medicine, Universidade Federal da Bahia, Brazil; the Department of Infectious and Parasitic Diseases, School of Medicina, Universidade Federal do Maranhão, Brazil; and the Centro de Pesquisas Gonçalo Muniz, Fiocruz, Bahia, Brazil.

Supported by United States Public Health Service Grant AI30639.

Address for correspondence: Achiléa Lisboa Bittencourt, Hospital Universitário Prof. Edgard Santos, Rua João das Botas, s/n, Canela - CEP, Salvador, Bahia, Brazil. out improvement. The dermatologic examination showed erythematous nodule lesions disseminated over the whole body, being more numerous on the upper and lower extremities. In the ears, the nodules show confluence, and in the malar region of the face, there are infiltrated plaques. The lower half of the nose is severely infiltrated conferring a tumor-like appearance (Fig. 1A). On the feet, two ulcerated tumor-like lesions measure $8 \times 7 \mathrm{~cm}$ and $5 \times 5 \mathrm{~cm}$. There are six other large ulcerations, with infiltrated borders and granulomatous bottom, the larger measuring $8 \times 5 \mathrm{~cm}$ and the smaller $3.5 \times 3 \mathrm{~cm}$, located on the feet and the anterior aspect of the left leg (Fig. 1B). There is also enlargement of the volume of all pododactiles, and thick and rough nails are observed. Immunoperoxidase staining using anti-Leishmania mexicana amazonensis amastigotes-specific monoclonal antibodies $^{6}$ showed a positive reaction confirming the species
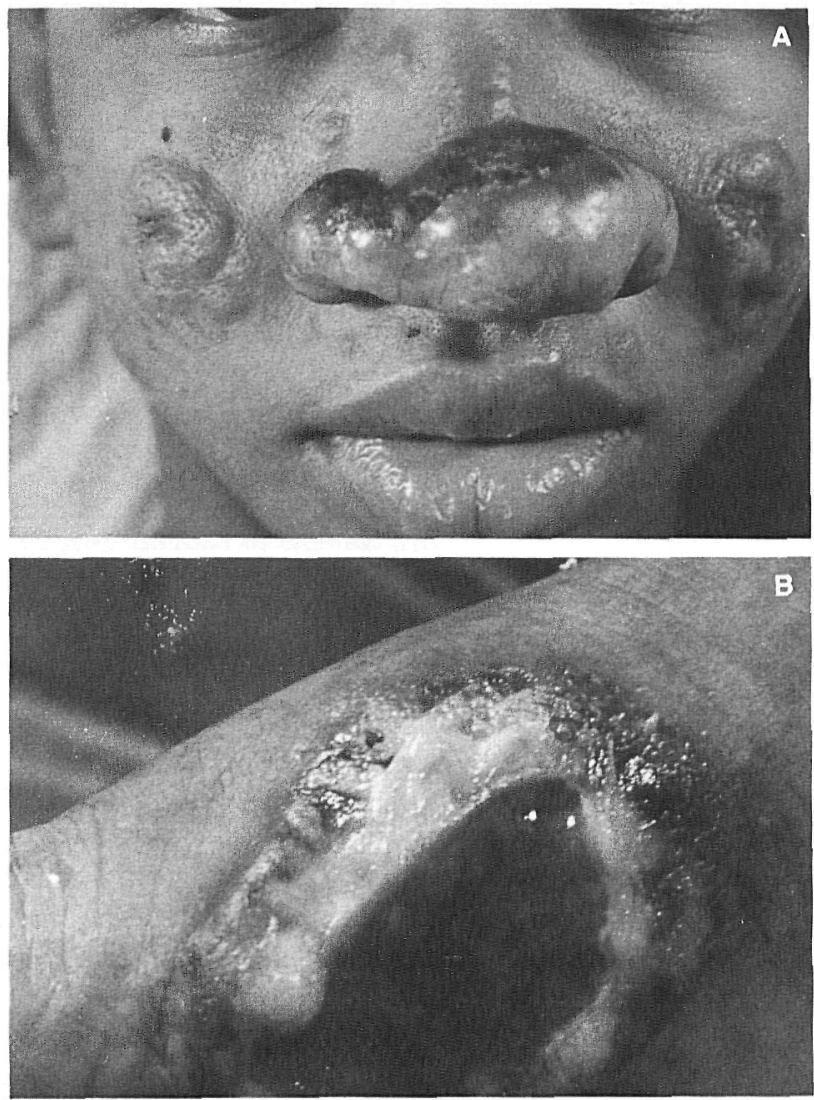

Figure 1. $A$, tumor-like lesion on the nose and infiltrated plaques in the malar regions. $B$, a deep ulcer on the foot. 
of the parasite present. Anti-Leishmania cell-mediated immunity, as tested by delayed type hypersensitivity reaction (Montenegro's test) and by lymphocyte transformation test ${ }^{7}$ was negative.

RESULTS

\section{Pathological Study}

Ulcer border. Sections exhibit moderate acanthosis and parakeratosis. In the dermis, there is infiltration of lymphocytes, plasma cells, macrophages, and eosinophils, and small focal areas of vacuolated and parasitized macrophages surrounded by mononuclear cells and eosinophils (Fig. 2A). In local areas, there is a predominance of eosinophils, many of them showing degranulation and parasites free in the interstice (Fig. 2B).

Nodule. The epidermis and a subjacent strip of connective tissue have a normal appearance. The dermis is diffusely infiltrated by vacuolated and parasitized macrophages with scattered plasma cells. Most of the macrophages have a moderate number of parasites, whereas some are heavily parasitized. Few parasites are present in the interstitial tissue.

\section{Ultrastructural Study}

Histopathologic differences were observed between the ulcerated lesion and the nodule. It is noteworthy that in ulcerated lesions there was a predominance of eosinophils among inflammatory cell infiltrate, which was also composed of macrophages, scarce lymphocytes, and plasma
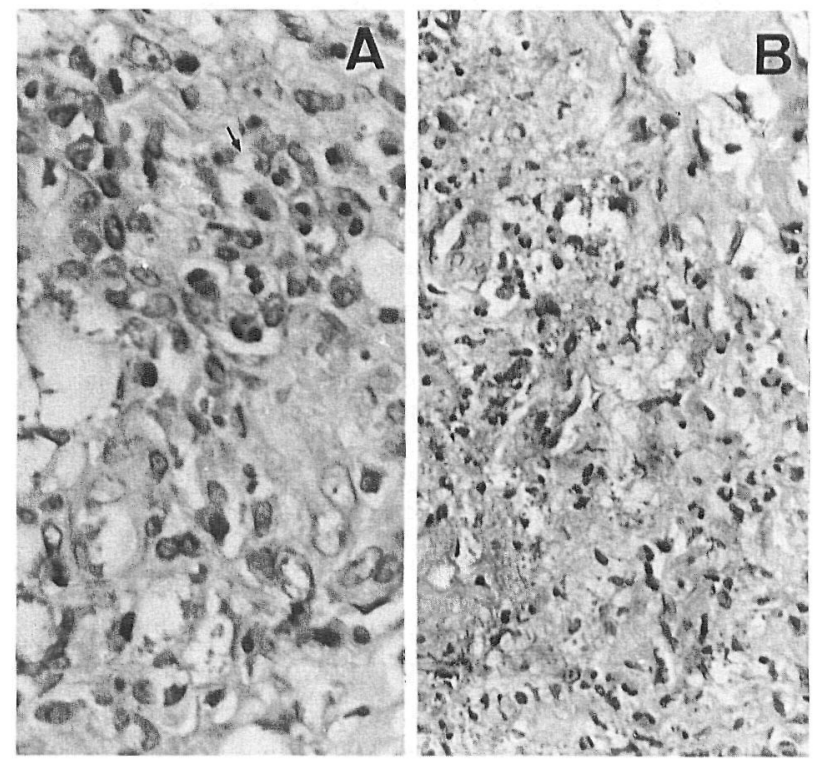

Figure 2. Ulcer. $A$, vacuolated and parasitized macrophages, some plasma cells, and on the right, eosinophils (arrow). $B$, amastigotes and cosinophil granules in the interstice associated with disintegrated eosinophils. (hematoxylin and eosin stains, original magnifications $\times 320(A), \times 192(B)$ )

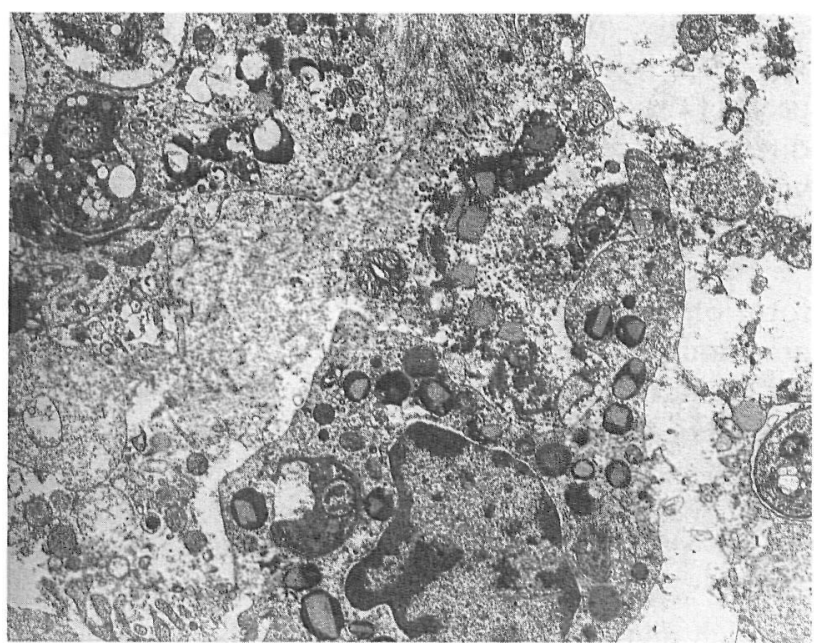

Figure 3. Ulcer. Eosinophils with damaged amastigotes. Parasites and granules are seen in the interstice. (original magnification $\times 7000$ )

cells. Many eosinophils were lysed, and their granules were seen in the interstitial space, sometimes close to macrophages. Few eosinophils contained amastigotes within parasitophorous vacuoles. Most of the parasites appeared degenerated in the interstitial tissue or phagocytized by macrophages. Generally such macrophages were lysed showing rupture of the cytoplasmic membrane. In the nodular lesion, the parasitism was more marked than in the ulcerated lesion, and macrophages predominated over eosinophils. A lot of degenerated or lysed amastigotes were seen in the interstice. Some eosinophils contained parasites within cytoplasmic vacuoles. Only a few macrophages were lysed.

\section{DISCUSSION}

This patient presented most of the characteristic aspects of DCL, such as nodular and infiltrative lesions - disseminated throughout the body with absence of mucosal involvement, a high parasite load in the lesions, lack of cell-mediated immune responses to Leishmania antigen, and a poor response to antimonial treatment. But different from the classical aspect of DCL, the patient presented large and deep ulcers and a great number of eosinophils in the inflammatory infiltrate. Ulcerations, when present in DCL, are superficial and small, but without the histopathologic aspects observed here, and appear on the surface of infiltrated lesions exposed to trauma. ${ }^{1}$ Considering the sites of the ulcerated lesions in the present case (feet and anterior aspect of the leg) and the fact that the patient has a history of disease dating from his first year of life (a child is considerably more exposed to trauma), these ulcerations could be related to trauma. Other factors may be involved in the pathogenesis of these lesions because they are very large and persistent and do not represent secondary lesions. 
Recently, two other cases of DCL with ulcerations were described, both having the immunopathologic aspects of this polar type of leishmaniasis. ${ }^{8,9}$ As antigenic differences can occur among isolates from patients with DCL, ${ }^{10}$ we can speculate if these atypical aspects are related to these antigenic differences.

These patients cannot be considered as borderline form of leishmaniasis, because they did not present granulomatous reaction. ${ }^{11}$ Similarly to other cases with the classical presentation of DCL, a predominance of degenerated and dead parasites, most of them in the interstice, were observed ultrastructurally. The presence of lysed amastigotes indicated a cell-mediated immune response, although it was unable to control the disease. ${ }^{12}$

One aspect never before observed in human DCL was the high number of eosinophils, being the predominant cell type in the ulcer and many of them exhibiting degranulation. The association of lysed parasitized macrophages, dead parasites, and eosinophils was frequently seen and may indicate a parasiticidal role of eosinophils. In the experimental infection of mice by $L$. amazonensis and L. mexicana, eosinophils can predominate in the infiltrate. ${ }^{13,14}$ The presence of these cells does not correlate with immune status, as they are observed in resistant (C57BL16) and susceptible BALB/c strains of mice and also in immunized and nonimmunized BALB/c. ${ }^{14} \mathrm{Sev}-$ eral yet untested hypotheses have been put forward concerning the parasiticidal action of eosinophils, either by phagocytosis, extracellular granule release, or by cooperation between eosinophils and macrophages. ${ }^{13,14}$ It has been suggested that the immune response in the mouse is dependent on the balance of the two helper $\mathrm{T}$ cells with largely diverse functional activities, Th1 or Th 2 cells..$^{15}$ In mice, high numbers of eosinophils are correlated to high levels of IL-4 and IL-5, lymphokines synthesized by Th2 lymphocytes ${ }^{15}$ and such cells are activated upon the infection of susceptible mouse strains by L. amazonensis. ${ }^{16-18}$ Although these types of clones have not been described in humans such a scenario would help to understand the presence of a partial unresponsiveness, but not anergy, in DCL patients, responsible for a very limited immune response, which may vary from lesion to lesion. A predominance of Th2 type cells would also explain the occasional findings of a predominant eosinophil infiltration in lesions from DCL patients.

\section{CONCLUSIONS}

This case demonstrated that ulceration can occur in DL not only related to trauma, and it is associated with a marked infiltration of eosinophils and ultrastructural indication of a parasiticidal action of these cells.

\section{REFERENCES}

1. Bittencourt AL, Guimarães N. Imunopatologia da leishmaniose tegumentar difusa. Med Cutan Ibero Lat Am $1968 ; 2: 395-402$.
2. Bittencourt AL, Freitas LAR. Leishmaniose tegumentar difusa. Aspectos anatomopatológicos. Med Cutan Ibero Lat Am 1983; 11:265-270.

3. Bryceson ADM. Diffuse cutaneous leishmaniasis in Ethiopia. I. The clinical and histological features of the disease. Trans Roy Soc Trop Med Hyg 1969; 63: 708 -737 .

4. Bryceson ADM. Diffuse cutaneous leishmaniasis in Ethiopia. Treatment. Immunological studies. Pathogenesis. Trans Roy Soc Trop Med Hyg 1970; 64:369-393.

5. Convit J, Pinardi ME, Rondon AJ. Diffuse cutaneous leishmaniasis: a disease due to an immunological defect of the host. Trans Roy Soc Trop Med Hyg 1972; 66: 603-610.

6. Bittencourt AL, Barral A, Jesus AR, et al. In situ identification of Leishmania amazonensis associated with diffuse cutaneous leishmaniasis in Bahia, Brazil. Mem Inst Oswaldo Cruz 1989; 84:585-586.

7. Carvalho EM, Johnson WD, Barreto E, et al. Cell mediated immunity in American cutaneous and mucosal leishmaniasis. J Immunol 1985; 135:4144-4148.

8. Guenoum FZ, Doukan S, Bouree P, et al. Une eruption cutanée diffuse et persistant chez une immunodéprimée. Ann Pathol 1990; 10:365-366.

9. Sharma VK, Kaur S, Mahajan RC, et al. Disseminated cutaneous leishmaniasis. Int J Dermatol 1989; 28:261262.

10. Leon LL, Machado GM, Paes LEC, et al. Antigenic differences of Leishmania amazonensis isolates causing diffuse cutaneous leishmaniasis. Trans Roy Soc Trop Med Hyg 1990; 84:678-680.

11. Morierty P, Bittencourt AL, Pereira C, et al. Borderline cutaneous leishmaniasis clinical, immunological and histological differences from mucocutaneous leishmaniasis. Rev Inst Med Trop (São Paulo) 1978; 20:15-21.

12. Bittencourt AL, Freitas LAR, Pompeu ML, et al. Distinct ultrastructural aspects in different biopsies of a single patient with diffuse cutaneous leishmaniasis. Mem Inst Oswaldo Cruz 1990; 85:53-59.

13. Grimaldi G, Soares MJ, Morierty PL. Tissue eosinophilia and Leishmania mexicana mexicana eosinophil interactions in murine cutaneous leishmaniasis. Parasite Immunol 1984; 6:327-338.

14. Pompeu ML, Freitas LAR, Santos MLV, et al. Granulocytes in the inflammatory process of BALB/c mice infected by Leishmania amazonensis. A quantitative approach. Acta Tropica 1991; 48:185-193.

15. Mosmann TR, Coffman RL. Heterogeneity of cytokine secretion patterns and functions of helper T cells. Adv Immunol 1989; 46:111-147.

16. Heinzel FP, Sadick MD, Holaday BJ, et al. Reciprocal expression of interferon gamma on interleukin 4 during the resolution or progressing of murine leishmaniasis. Evidence for expansion of distinct helper T cell subsets. J Exp Med 1989; 169:59-72.

17. Sadick MD, Heinzel FP, Holaday BJ, et al. Cure of murine leishmaniasis with anti-interleukin 4 monoclonal antibody. Evidence for a T cell - dependent Interferon gamma-independent mechanism. J Exp Med 1990; 171:115-127.

18. Scott P, Natovitz P, Coffman RL, et al. Immunoregulation of cutaneous leishmaniasis. T cell lines that transfer protective immunity or exacerbation belong to different $\mathrm{T}$ helper subsets and respond to distinct parasites antigens. J Exp Med 1988; 168:1675-1684. 
This document is a scanned copy of a printed document. No warranty is given about the accuracy of the copy. Users should refer to the original published version of the material. 